\title{
A divulgação da avaliação da educação na imprensa escrita: 1995-2010
}

\author{
José Carlos Rothen \\ Gladys Beatriz Barreyro \\ Aryane de Paula Prado \\ Leticia Bortolin \\ Raiani Cristina Cavachia
}

Resumo: A imprensa, a partir de meados da década de 1990, tornou-se um dos atores importantes para a consolidação das políticas de avaliação da educação na realidade brasileira. Usando como fonte documental o jornal Folha de S. Paulo, as revistas Veja e Época, no período compreendido entre 1995 e 2010, no artigo reconstrói-se a maneira como estes meios de comunicação impresso divulgam e fazem uso dos resultados das avaliações. Conclui-se que as mídias analisadas têm contribuído para a legitimação da avaliação da educação e é presente nas matérias a ideia de que a avaliação é uma prova que permite controlar a qualidade da educação.

Palavras-chave: Avaliação da educação. Imprensa. Políticas educacionais.

The disclosure of the assessment of education in the printed press: 1995-2010

Abstract: The press media, from the mid-1990s, has become one of the key players for the consolidation of educational evaluation policies in Brazil. Analyzing the Folha de São Paulo newspaper and Veja and Época magazines, in the period between 1995 and 2010, the paper reveals the way the press media advertises and uses evaluation results. It is concluded that the analyzed media have contributed to the legitimization of educational evaluation. Present in the articles is the notion that evaluation is a test that makes possible the control of the quality of education.

Keywords: Educational evaluation. Press media. Educational Policies. 


\section{Introdução}

A avaliação da educação começa a tomar repercussão social no Brasil com a Reforma do Estado, implantada a partir de 1995. Esta repercussão tem impulso inicial com a implantação do Exame Nacional de Cursos (ENC), que objetivava controlar a qualidade das instituições de educação superior privada, que tiveram exponencial expansão no período. Com repercussão inicial menor e que, gradativamente se aumentou, reforçou-se a política de avaliação do ensino fundamental com o Sistema de Avaliação da Educação Básica (SAEB) e do ensino médio com o Exame Nacional de Ensino Medio (ENEM) ${ }^{1}$.

O ENC, que ganhou o apelido de Provão, foi uma prova em larga escala²; aplicado a poucos cursos, mas ampliado ano após ano, pois se visava incorporar todos os cursos do país. A divulgação dos resultados de forma simplificada, apesar de poder gerar distorções, favorecia a comparação dos resultados das instituições e a elaboração de rankings que estimulavam a concorrência entre cursos e instituições (ROTHEN, 2003). Além de inovar com a aplicação da prova, o Ministério de Educação teve uma estratégia destinada à divulgação dos resultados pela mídia o que permitiu construir "junto à população, a ideia de que os exames eram um mecanismo de controle de qualidade ainda que, apos a divulgação, não houvesse consequências para os cursos com maus resultados" (TAVARES et al., 2011, p. 88).

A imprensa foi um ator relevante na história recente da avaliação da educação básica e superior, pois a divulgação dos resultados teve e tem eco na imprensa, que segue duas tendências no tratamento da temática: a primeira, sensacionalista, destaca os aspectos negativos; a segunda, ranqueadora. Essas tendências colaboram, nos governos Fernando Henrique Cardoso (FHC) (1995-2002), para a implantação da política para a educação superior ,que tinha como norte a regulação das instituições pelo mercado. Nessa nova política, a avaliação e, especialmente, o Provão, inaugurou uma relação privilegiada com a mídia, em sua divulgação massiva, que gradativamente foi se expandido para a avaliação da educação básica.

Esse texto, elaborado no marco da pesquisa Políticas de expansão e avaliação da educação superior no Brasil pós LDB/96, realizada pelo grupo de

1 Efetivamente, o ENEM não poder ser considerado uma avaliação do Ensino Médio, pelo fato de a realização da prova ser facultativa aos alunos.

2 As avaliações de larga escala são construídas com o objetivo de avaliar e comparar realidades institucionais distintas; para tanto, utilizam-se instrumentos e critérios de valoração unificados. No caso de provas de larga escala aplica-se uma mesma prova a todos os alunos das instituições educacionais avaliadas. 
pesquisas Universitas/BR trata sobre as relações das políticas de avaliação da educação básica e superior com a impressa escrita.

Foram escolhidos para a pesquisa: a revista Veja (publicada pela Editora Abril), a revista Época (Editora Globo) e o jornal Folha de S. Paulo (editado pela Folha da Manhã); na seleção dos veículos utilizou-se como critério o fato de terem circulação nacional e de disponibilizarem o conteúdo da versão impressa na Internet. Como delimitação temporal, adotou-se o período corresponde ao primeiro ano dos governos FHC, 1995, e o último ano dos governos Luiz Inácio Lula da Silva, 2010. No caso da revista Época investigou-se entre os anos de 2003 e 2010 , por estarem disponíveis na internet apenas os números posteriores ao de 06 de março de 2003.

A Folha de S. Paulo disponibiliza a versão online das matérias da versão impressa no Portal UOL e, atualmente, é divulgado o fac-símile do jornal (que não foi utilizado nesta pesquisa por não estar disponível no seu início). No acervo online há ferramentas de busca que permitem conciliar a procura por palavras-chave e período. Considerando o nível de ensino elegeu-se as seguintes palavras chaves: para a educação básica, "SAEB", "SARESP", "ENEM", "Prova Brasil", "Provinha Brasil", "ENCCEJA" e "PISA"; para educação superior, "Provão", "ENC", "Exame Nacional de Cursos", "Avaliação das condições de oferta", "SINAES", "Sistema Nacional de Avaliação da Educação Superior", "ENADE”, "Exame Nacional de Desempenho do Estudante".

A revista Veja disponibiliza o fac-símile da versão impressa; a revista Época disponibiliza todos os artigos organizados por edição. Como a quantidade de revistas não é volumosa optou-se, então, pela leitura do título das reportagens para selecionar os artigos relevantes para a pesquisa.

Nos procedimentos iniciais de identificação dos artigos das revistas observou-se, primeiro, as edições tendem a priorizar um único assunto de maior repercussão na semana -por exemplo, no caso dos atentados de 11 de setembro de 2001, a Veja destinou por semanas seguidas parte significativa das suas edições na sua cobertura -, segundo, as temáticas relacionadas à educação tem pouca divulgação nas duas revistas, e menos ainda, a questão da avaliação. Optou-se por selecionar todos os artigos relacionados à educação.

Em muitas das matérias das revistas e da Folha de S. Paulo, os jornalistas responsáveis são identificados, neste caso, na exposição dos resultados ao indicar a fonte primária da pesquisa optou-se por utilizar o nome do jornalista e quando não há identificação, utilizou-se o nome do veículo. 


\section{Avaliação em Revista}

\subsection{Revista Veja}

As temáticas publicadas na Veja, entre os anos de 1995 e 2010, relativas à educação são: baixa qualidade da educação, política educacional, projetos e investimentos, avaliação da educação.

Na revista, encontra-se o discurso de que a educação básica pública e a educação superior privada no Brasil são de péssima qualidade; de forma não sistemática são apontadas diversas causas como explicação, por exemplo, os profissionais da educação tem formação precária em universidades privadas (VEJA, 1995a, p. 48), também se destaca a questão dos baixos salários dos professores. Em 2006, o articulista Claudio de Moura Castro (2006, p. 22) ao analisar o "fracasso" brasileiro apresentado nos resultados do Pisa, aponta para a necessidade de melhorar a qualidade da educação básica, na sua visão a grande procura de alunos pela educação superior é uma prova de que a educação básica é de péssima qualidade, parte da população entenderia que "o curso superior é uma solução, diríamos, um remendo. O problema está nos níveis anteriores". Apesar do continuo diagnóstico negativo da qualidade da educação, a Veja também apresenta matérias que ressaltam experiências bem sucedidas e um discurso otimista em relação ao futuro.

Ao tratar das temáticas sobre políticas educacionais, projetos e investimentos, a revista demonstrava uma postura favorável ao governo FHC e ao seu Ministro da Educação Paulo Renato Souza. Frequentemente, trazia reportagens destacando ações governamentais positivas para a educação. Alguns exemplos: em 1995, relatou que a ênfase das políticas educacionais do novo governo dirigia-se para a educação básica e que haveria aumento de salário dos professores; em 1996 apreciou positivamente a emenda constitucional que fundamenta o Fundo de Manutenção e Desenvolvimento do Ensino Fundamental e de Valorização do Magistério (FUNDEF); em 1997; apoiou a proposta do Ministro da Educação de reformulação do ensino técnico e, em 1998, destacou as mudanças promovidas pelo governo federal estariam agindo no sentido de resolverem os problemas da educação brasileira. O apoio da revista é explicito no texto do editor chefe Roberto Civita (1996, p. 102), em que assinala ser preciso

Continuar pelo bom caminho iniciado pelo Ministro da Educação ao partir para uma reformulação total do nosso sistema educacional, sem o qual não há país desenvolvido e não há futuro.

Embora se trate de trabalho para várias gerações, urge começar, como tem reiterado o Ministro Paulo Renato, pelo treinamento de profes- 
sores, pela valorização do seu trabalho e pela ênfase na melhoria do ensino fundamental.

Em 2007 a revista publicou noticias sobre o IDEB, Castro (2007, p. 20) em sua coluna argumentou a favor de medir-se a qualidade da educação usando índices educacionais. Em favor destas medidas a revista também entende que elas poderiam favorecer ações meritocráticas, pois dariam subsídios para premiar o esforço das escolas em melhorarem (BETTI, 2008, p. 100), permitindo a implantação de uma gestão empresarial na educação.

Em 2008, tendo como referência o modelo de gestão empresarial, em entrevista Maria Helena. Castro, argumentou que assim como "há inspetores de qualidade nas fábricas e a Prova Brasil na escola" ele continua

Das empresas bem administradas afloram conselhos proveitosos para escolas: clareza ao definir (poucas) metas e assegurar que sejam compartilhadas (por diretores, alunos e professores); avaliação dos processos e a regra pétrea de que é preciso tomar providências quando os resultados não correspondem o esperado. Nada disso fere a sacrossanta nobreza da educação nem a complexidade e a delicadeza dos seus processos. De fato as melhores escolas seguem tal figurino (CASTRO, 2008, p. 20).

A avaliação é um tema marginal na revista, como as outras temáticas relacionadas à educação, sendo a sua maior presença nos artigos assinados pelo articulista Claudio de Moura Castro. Como todo articulista, as sua opiniões não são o posicionamento oficial do meio de comunicação que publica os artigos, contudo na análise dos seus artigos e das outras matérias da revista observa-se um relativo alinhamento entre elas.

A revista não tem a preocupação em divulgar os resultados das avaliações, contudo divulga um discurso defendendo a ideia de que estas são instrumento de melhoria da educação, ao promover a concorrência entre as instituições de educação superior. Os resultados da avaliação apesar de não divulgados são utilizados como argumentos para fundamentar críticas, comparações e opiniões.

No inicio do governo FHC, em 1995, a revista publicou duas matérias relativas à avaliação. Uma, apontando os benefícios que a avaliação da educação, em conjunto com uma política de "reciclagem" do magistério, estaria trazendo à educação do Estado de Minas Gerais (VEJA, 1995b, p. 25).

A segunda matéria é de divulgação da ideia da implantação do Exame Nacional de Cursos. A revista apontava que o Exame permitiria identificar as Instituições de péssima qualidade e fechá-las. Cita como exemplo, uma 
universidade que oferecia irregularmente cursos de fim de semana: segundo a Veja, os seus alunos teriam dificuldades com a realização do Exame. A única dificuldade apontada pela revista seria do risco da proliferação de cursinhos para o Exame. (Veja, 1995b, p. 48). No ano da realização do primeiro Provão, 1996, a revista trouxe três matérias (GÓIS, 1996, p. 56-7; VEJA, 1996, p. 57; CAMAROTTI, 1996) sobre o Exame que seria aplicado e a resistência dos estudantes em o realizarem. Além de apresentar a reação negativa da União Nacional dos Estudantes (UNE) ao Exame, a Revista destacava que os alunos não teriam prejuízos com a prova, mas as instituições sim. Na última reportagem apresentava a avaliação que seria realizada, como similar à realizada, pela CAPES na pós-graduação, que tinha o ranqueamento das Universidades, como uma das características. Em dezembro do mesmo ano, Castro (1996, p. 150) na sua coluna, defendia a importância dos Exames como processos de avaliação destacando, para a educação básica, as avaliações realizadas pelos Estados de Minas Gerais e São Paulo. Comparando com a avaliação da CAPES, defendia que a avaliação da educação superior permitiria realizar comparações entre as Instituições, premiando as melhores e dando oportunidades para as que ficam para trás.

Com a aplicação do Provão, a revista, nas poucas matérias sobre a temática, deixa de dar ênfase no boicote estudantil, mantendo constante a ideia de que a sua realização é um grande avanço que permite o conhecimento da realidade; nas palavras da revista: "depois de décadas trabalhando às cegas, finalmente o Ministério da Educação e Cultura, MEC, tem um retrato do ensino universitário nacional" (ONIGRE, 1997, p. 86). Na linha de discussão da revista duas questões aparecem: a primeira, se as instituições públicas são melhores ou piores que as particulares; a segunda, se há influência de professores mestres e doutores na qualidade do curso. Nas duas questões, a revista oscila no seu diagnóstico: por exemplo, em abril de 1997, em entrevista, Castro afirmou que o teste teria mostrado que "não existe relação direta entre corpo docente cheio de mestres e doutores e boas notas no Provão" (ONIGRE, 1997, p. 87). Em contrapartida, na reportagem de Cruz (1998, p. 94-5) assinala-se que um dos motivos para a qualidade das universidades federais é a grande presença de professores titulados.

Em relação à qualidade das instituições particulares, a revista analisa os resultados apontando que as Instituições que obtiveram as piores notas são particulares e, em sentido contrário, reproduz a fala do Ministro Paulo Renato de Souza de que teria sido derrubado o mito de que as universidades pagas são ruins. (ONIGRE, 1997, p. 86-7). 
$\mathrm{Na}$ análise dos resultados do Provão, a revista crítica o fato de que a maioria das Instituições obteve o conceito C, evitando embates com as Instituições e ao mesmo tempo não reconhecendo que a situação da educação superior seria ruim, na interpretação da revista "foi usado um critério digamos, tucano" (ONIGRE, 1997, p. 86-7), ou seja, evitou-se conflitos com as Instituições.

Sem ser efetivamente uma crítica, em 1998, Castro (1998, p. 23) apontou que os resultados da prova não permitiram fazer afirmações taxativas sobre a qualidade dos cursos de educação superior, pois a prova apenas compararia as instituições, o que não seria um defeito da prova, mas sua característica. Em 2002, ele afirmou que um dos efeitos colaterais do Exame é que ele poderia tornar os currículos rígidos (CASTRO, 2002, p. 20).

Ao diagnosticar os motivos para uma Instituição ter conceitos negativos, a revista elenca dois: para as públicas, os alunos teriam realizado boicote, e para as privadas, os seus alunos seriam oriundos de escolas de educação básica de péssima qualidade. Segundo Castro (1998, p. 23), “o próximo passo é valorizar quem eleva o nível dos alunos vítimas do ensino médio público e puxar as orelhas de quem está oferecendo um ensino superior incompetente”.

Em 2008, mesmo antes de o ENEM ser uma alternativa para substituir os vestibulares, a revista se posicionou de forma favorável a esta substituição, como por exemplo, ao publicar a opinião de Claudio de Moura Castro segundo a qual os exames são caros, cada opção de Instituição implica tem um exame a fazer em lugares diferentes, com custos de deslocamentos, gerando a exclusão de muitos candidatos por não terem condições de fazer tantas provas. Ele defendeu um vestibular único, com testes baseados nos ensinamentos do ensino médio. Esse "vestibular" seria o ENEM, mas afirmou que apesar dele vir melhorando seria preciso ainda mais melhoria. A partir de 2009, quando houve o primeiro caso do vazamento da prova, a revista apresentou reportagens com base nas investigações, afirmando que houve falhas e que o exame poderia perder a credibilidade, o mesmo em 2010 quando novamente houve problemas com o exame.

Na revista, é presente durante todo o período analisado (1995-2010), principalmente nos artigos de Castro, a ideia de que a aplicação das avaliações contribuiria para a melhoria na qualidade do ensino. Os testes diferenciariam as boas instituições de ensino das de péssima qualidade, e para as instituições mal classificadas, ter-se-ia o estimulo de melhoria de seus currículos, professores, materiais didáticos e a infraestrutura educacional. Por exemplo, em 1999 destaca-se que a Universidade Estadual de Londrina (UEL) teria aumentado a relação candidato/vaga por causa dos bons resultados no Provão 
(VEJA, 1999, p. 64). Em 1998, Castro (1998, p. 23) afirmou que o Provão teria facilitado aos alunos a escolha das escolas e aos empregadores a procura dos futuros empregados nas melhores escolas. Em 2000, destaca que o Brasil teria o mais completo sistema de avaliação (CASTRO, 2000, p. 21). No mesmo ano afirmou em entrevista Karin Finkenzeller (2000, p. 164-5) que as instituições mal avaliadas estão investindo para melhorarem o seu desempenho, que "chuchus-podres" não teriam como sobreviver à concorrência do mercado e nem atender as exigências do MEC (WEINBERG, 2000, p. 98). Em 2001, a revista assinalou que as Universidades bem classificadas utilizam os resultados como propaganda e que as mal classificadas estariam investindo na modernização (AMARAL, 2001, p. 116-7). Em 2002, Castro (2002, p. 20), em defesa dos testes, afirmou que eles permitiriam comparar e situar as escolas ou os alunos em um universo amplo. No primeiro ano do governo Lula, e durante os trabalhos da Comissão Especial instituída para elaborar uma nova proposta de avaliação, Castro (2003, p. 22) reforça a ideia de que o Provão permitiu a comparação e o ranqueamento dos cursos e teria estimulado a busca da melhoria pelos cursos ruins. Depois da instituição legal do Sistema Nacional de Avaliação da Educação Superior (SINAES), a revista publica matéria mostrando que a forma como os conceitos eram atribuídos mais escondiam a realidade do que a mostravam, pois cursos com nota A teriam desempenho ruim, mas reforça a ideia de que a obrigatoriedade da realização da prova teria levado à melhoria do ensino nas faculdades (WEINBERG, 2004, p. 84-95).

A visão favorável as avaliações ficou explicita na revista, como exemplo, em uma reportagem de 2006 na qual Castro (2006, p. 23) argumentou que o Provão foi um programa único no mundo, invejado pelos educadores estrangeiros. Essas avaliações permitem fazer ranque, possibilitando a escolha das melhores universidades e escolas.

\subsection{Revista Época}

No período de investigação (2003 a 2010) a educação na revista Época é tratada de forma marginal, com número pequeno de noticias, sendo 39 no período correspondente ao primeiro governo Lula (2003-2006) e 89 no segundo governo Lula (2007-2010). Identificaram-se as seguintes temáticas tratadas nas matérias: propostas políticas para a educação; sistema de cotas; investimentos no mercado educacional; os fracassos e sucessos do ensino; ENEM; qualidade da Educação Superior. 
A maioria das reportagens foi elaborada a partir de políticas públicas implantadas pelo Ministério da Educação. no primeiro ano do governo Lula as reportagens da revista são mais críticas do que nos anos posteriores, observa-se que boa parte das críticas eram reprodução da fala do então Ministro Cristóvam Buarque, (janeiro/2003 a janeiro 2004) não diminuindo as críticas com o seu sucessor Tarso Genro (janeiro/2004 a julho/2005), mas mudando significativamente no período do Ministro Fernando Haddad (julho/2005 a janeiro/2012).

A temática da reserva de vagas nas Instituições de Educação Superior públicas para alunos de escolas públicas e para etnias é recorrente na revista. Em geral, as matérias trazem depoimentos contrários a esta política pública e, apesar de a revista sempre apoiar-se em falas de outros, é muito claro o seu posicionamento contrário. São apresentados diversos argumentos contrários, por exemplo, na matéria de Paulo Moreira Leite (2003) que afirma que a política é importada dos Estados Unidos, onde haveria efetivamente racismo e que o Brasil seria um país mestiço; ou ainda, reproduzindo a fala de um índio terena de que o problema das cotas não resolveria o real problema da qualidade da educação básica (FRUTUOSO, 2004) e nem, segundo o Reitor da USP, a política de cotas resolveria o problema da falta de vagas nas universidades (AMORIM, 2005). Apoiando-se na fala de uma mãe de uma aluna negra, afirma-se que as cotas seriam injustas com os pais que colocam os seus filhos em escolas particulares procurando um bom ensino, por diminuir a oportunidade de seus filhos em ingressarem na educação superior (FERNANDES, 2006). As cotas, segundo um senador de Goiás, criariam uma tensão racial no país, pois as pessoas deixariam de ser denominadas brasileiras e passariam a ser denominadas por sua raça (RANGEL, 2009).

Em algumas matérias, a educação é apresentada como mercadoria que atrai investidores, os quais teriam no Provão uma medida de controle de qualidade (ÉPOCA, 2003), relata que professores estariam organizando-se em empresas para oferecerem o seu trabalho às Instituições, aumentando os seus rendimentos e possibilitando a diminuição das mensalidades (TERMERO, 2004), a revista relata que duas Universidades particulares ofereciam a possibilidade do aluno cursar uma graduação e uma pós-graduação em quatro anos, ao discutir se a proposta se seria correta ou não, a revista afirma: “o MEC questiona, mas o que diz o mercado?" (FRANCO, 2010). Interessante notar que, nesta matéria, o "mercado" é mais importante para avaliar do que o MEC.

É constante na revista que a qualidade da educação pública brasileira é ruim. Para a realização deste diagnóstico normalmente utiliza-se de estudos ou avaliações promovidas pelo Ministério da Educação. Por exemplo, a partir do 
documento "A geografia da educação brasileira"afirma-se que uma geração de jovens teve poucos benefícios da experiência escolar (VICÁRIA; CORDEIRO, 2003), ou utilizando os dados do Sistema de Avaliação da Educação Básica, afirma-se ser necessário um aumento do investimento da educação pois o desempenho dos estudantes teria sido o pior dos últimos dez anos (ARANHA, 2007b).

$\mathrm{Na}$ Época, encontram-se comumente três soluções para a melhora da educação: utilização da informática, formação dos professores e políticas de cobrança com caráter meritocrático. Em relação à informática, tem-se matérias prevendo o uso de novas tecnologias pelos professores (DUARTE, 2004), o uso de computadores revolucionando o ensino (BANÉ, 2007) e o uso da internet para intensificação do relacionamento professor/aluno (COTES; CARVAS, 2004; COTES; MONTEIRO, 2007).

Ao mesmo tempo em que o investimento na formação dos professores é apresentado como solução para os problemas da educação, a má formação é sempre uma das explicações para a sua deficiência, por exemplo, em 2003, ao expor o resultado de uma pesquisa realizada pela Fundação Carlos Chagas, segundo a qual a maioria das crianças termina o primeiro ano sem saber ler, apresenta-se como causa professores mal capacitados, escola pouco estimulante e não cumprimento dos 200 dias letivos (COTTES, 2003a) ou ainda, quando discute a questão do piso salarial dos docentes aponta que a questão salarial é apenas um fator, pois há muitos professores com carência de formação.

Antes de ser lançado oficialmente o Plano de Desenvolvimento da Educação (PDE) foi saudado pela revista por prever metas a serem atingidas e por criar um sistema de cobrança e meritocrático; nas palavras da revista: "O governo planeja instituir a meritocracia no ensino público. Agora, a ideia precisa resistir à pressão política" (ARANHA, 2007a). Ao ser lançado o plano, a revista elogiou "o plano de ministro Fernando Haddad é o primeiro que tem metas e um sistema claro de cobrança de resultados. Porque essa é a maior esperança para o ensino brasileiro" (ARANHA; CLEMENTE, 2007).

O ENEM como substituição aos vestibulares teve repercussão positiva na Época, da mesma forma que na Veja, mesmo antes da proposta governamental de o ENEM constituir-se um processo seletivo unificado, ela defendia que a prova tivesse esta finalidade. Reproduzindo o depoimento de educadores, apontava que o vestibular seria massacrante e que não adiantava ter apenas conteúdos decorados, mas um conhecimento criativo, preparando o aluno para a vida (VASCONCELOS, 2007). O ENEM também é visto como um referencial oficial que permitiria a comparação de escolas, isto apesar de a realização ou não da prova ser uma ação voluntária dos alunos (VICARIA, 2008). Em outra 
reportagem, aponta que o ENEM não fixaria padrões de qualidade, por isso ao lerem os resultados, os pais deveriam comparar a nota de colégios similares. Ainda afirmou que o "Enem é o instrumento mais confiável para julgar o nível dos colégios particulares" (ARANHA, 2009).

A defesa da realização do Exame continuou mesmo quando em 2009 começaram a surgir problemas de vazamento do conteúdo da prova. Em uma matéria com o título sugestivo "A falha não é do ENEM", a revista apresenta a ideia de que não seria a credibilidade do Exame que estaria em jogo, mas sim do INEP, órgão responsável pela realização da Prova (GUIMARÃES, 2010).

Da mesma forma que trata da educação básica, a revista considera as Instituições de Educação Superior brasileiras de baixa qualidade, diante deste fato umas das opções apresentadas é a realização de cursos no exterior. Nesta linha, uma das possibilidades apontadas seria o convenio de algumas universidades brasileiras com estrangeiras o que permitira ter uma dupla titulação: brasileira e estrangeira (COTTES, 2003b). Na revista, encontra-se também a ideia de que a expansão das Instituições no Brasil é muito recente, o que teria permitido que em alguns cursos como Moda, Tecnologia e Design que não tem o nível excelência no Brasil, as pessoas busquem a solução em cursos no exterior (VICARIA, 2007).

\subsection{Avaliação em Folha}

A temática da avaliação da educação no Jornal Folha de S. Paulo tem um espaço muito maior do que nas revistas analisadas, tanto que foi localizado no período compreendido entre 1995 e 2010 um total de 1925 reportagens sobre a temática, sendo 773 sobre a educação superior e 1152 sobre a educação básica. O número exponencialmente maior das reportagens encontradas na Folha, tendo em comparação as revistas, pode ser explicado pela razão de que o jornal, além de publicar um número de páginas muito maior, tem edição diária enquanto que as revistas são semanais.

Durante o período analisado, o número de reportagens aumentou gradativamente. Em1995, se localizaram apenas 19 matérias; no ano seguinte passou para um total de 76 e assim sucessivamente. Nos três primeiros anos pesquisados, há o domínio de matérias sobre a avaliação da educação superior principalmente pela divulgação da repercussão da aplicação do Provão e de seus resultados. Em 1998, à educação básica é dedicado um número maior de reportagens versando sobre o Sistema de Avaliação da Educação Básica (SAEB), Sistema de Avaliação de Rendimento Escolar do Estado de São Paulo (SARESP) e do Exame Nacional de Cursos (ENEM). 
A participação da avaliação da educação básica em relação com as de educação superior, nas matérias sobre a avaliação da educação gradativamente aumenta, sendo que a partir de 2004 em todos os anos ela representa mais de $50 \%$ do total, sendo que em 2009 e 2010 ela tem mais de $80 \%$. Levantamos as seguintes hipóteses para explicação deste fato:

a) durante o governo FHC, com a aplicação do Provão, a avaliação da educação superior foi central nas políticas para está área;

b) no governo Lula, a avaliação perdeu a centralidade nas políticas governamentais, assim outras políticas (como o Plano de Desenvolvimento da Educação) e temas sobre a educação superior (como a questão das cotas nas universidades federais) ocupam o espaço destinado à educação

c) apesar de a aplicação de provas como instrumento de avaliação da educação básica ser anterior, elas passam a ter maior divulgação apenas após a aplicação do Provão;

d) a partir de 2008, com as alterações ocorridas no ENEM para que este substituísse os exames vestibulares e, com as fraudes ocorridas na aplicação das provas, diminuiu o número de noticias das outras avaliações da educação e aumento significativamente as noticias relativas ao ENEM.

São marcantes, nas reportagens da Folha de S. Paulo, três características: o enfoque pluralista, o uso intensivo de ranque e a tônica sensacionalista. Apesar de o jornal ter um posicionamento claro sobre o papel das avaliações, que discutiremos adiante, a sua linha editorial é marcada por apresentar posicionamentos diferentes sobre a temática, em alguns momentos apresentando-se como tribuna para o debate.

Por exemplo, em 1996, é publicada a posição do, então presidente da União Nacional dos Estudantes (UNE) Orlando Silva Junior (1996) criticando severamente o Provão, e por outro lado, o prof. Sérgio Henrique Ferreira (1996) a visão de que a longo prazo, pode "fornecer subsídios para o desenvolvimento de políticas que estimulem a expansão e a melhoria dos estabelecimentos e universidades orientados para a qualidade acadêmica". Ainda a manifestação do, então, Ministro da Educação de que o Provão seria um instrumento válido para a avaliação do ensino superior, em contraponto, apresenta-se a análise de Ana Mercês Bahia Bock (1996), segundo a qual "a redução da avaliação das 
universidades ao provão traria como consequência um retrocesso nas concepções e formas de ensinar".

Com frequência, o jornal - tendo como base os resultados das avaliações apresenta algum tipo de ranque das instituições. E é muito claro o posicionamento do jornal de que o ranque, além de ser útil para que os alunos escolham as escolas que pretendem estudar, estimula a concorrência entre as instituições escolares, aumentando assim a qualidade do ensino. É representativo desta posição, o editorial intitulado "Provão e o futuro do ensino", no qual ao analisar a recusa da realização do exame afirma que:

As escolas superiores que se recusaram a fazer as provas em 96, muitas de bom nível, voltaram atrás em 97, talvez por causa do vexame da má colocação no ranking universitário do país. Instaura-se um clima de competição saudável (FOLHA DE S. PAULO, 1997b).

As reportagens que acompanham a divulgação de ranques são elaboradas no formado de denuncia daquilo que em alguns momentos o Jornal denomina como a "tragédia brasileira", enfatizando principalmente os aspectos negativos apresentados pelas avaliações.

No jornal, é muito clara a ideia de que o antigo Provão seria, por excelência, o mecanismo de avaliação da educação, tanto que em alguns momentos a palavra "Provão" tornou-se sinônimo de avaliação. Por exemplo, nas primeiras aplicações do SARESP ele foi apresentado como o "provão paulista", (FOLHA DE S. PAULO, 1997d), o mesmo ocorrendo nas primeiras discussões sobre o ENEM, que é apresentado como o "provão do $2^{\circ}$ grau" (FOLHA DE S. PAULO. 1997c). Mesmo depois que o Provão foi substituído pelo ENADE, ele continuou ainda designando avaliação em geral como ocorreu em uma notícia intitulada "em “provão', paciente do SUS 'reprova' HC de SP (FOLHA DE S. PAULO, 2009).

No jornal não encontramos nenhum tipo de questionamento relativo à qualidade dos instrumentos de avaliação e da validade dos resultados, ou seja, as provas aplicadas seriam fieis representações da realidade. Um dos exemplos, no momento que foram divulgados os resultados do ENEM o jornal reproduz uma fala do então Ministro da Educação Paulo Renato de Souza analisando os resultados.

Os alunos do $2^{\circ}$ grau estão com uma formação sofrível. Nós estamos com acerto médio em português de cerca de um terço das perguntas, e em matemática, abaixo disso. Nós temos que investir muito mais nas questões que têm a ver com qualidade", afirmou Paulo Renato" (FOLHA DE S. PAULO, 1998a). 
De certa forma, é de esperar que o Ministro da Educação, ao divulgar o resultado das avaliações realizadas, confie nos dados que ele mesmo apresenta, mas no jornal o dado é tomado de forma acrítica, ou seja, ele é uma fiel representação da realidade. A partir da analise dos resultados "verdadeiros" das avaliações, é que o jornal assume a sua postura crítica. Por exemplo, em 1998 ao analisar os resultados negativos do SARESP, no editorial do jornal afirma-se:

Foi submetido a teste cerca de 1 milhão de crianças de $4^{\mathrm{a}}$ e $8^{\mathrm{a}}$ séries da rede pública estadual paulista. Conclusão: apenas $15 \%$ dos alunos terminam hoje o $1^{\circ}$ grau dominando simples operações de multiplicar e dividir. Ou seja, milhares de jovens, muitos deles obrigados a interromper os estudos para ingressar prematuramente num mercado de trabalho cada vez mais exigente e competitivo, saem do ciclo básico com terríveis carências (FOLHA DE S. PAULO, 1998b).

É recorrente, no período investigado, a compreensão de que as avaliações contribuem expressivamente para a melhoria da qualidade da educação, principalmente pelo fato de pressionarem as escolas a buscarem a melhoria dos seus métodos de ensino.

De todo modo, o provão e as avaliações concomitantes já serviram para que estudantes e diretores de escolas superiores se empenhem mais ativamente em buscar qualidade, um tema que, se estava na agenda das discussões sobre ensino superior, não era objeto de medida prática visível. O sistema de avaliação -apesar de falhas que podem aos poucos ser sanadas- é um passo necessário para a melhoria da competência nacional (FOLHA DE S. PAULO,1997b).

Além de estimular as instituições a buscarem a melhoria de suas práticas educacionais, é presente no jornal a ideia de que ela teria importante papel no controle pelo estado das instituições e professores. Por exemplo, em 2006 ao analisar a possibilidade de os Conselhos Profissionais participarem dos processos de avaliação do Ministério da Educação, o jornal em seu editorial entende que cruzar os pareceres dos Conselhos "com os dados recolhidos pelos mecanismos de avaliação já existentes pode ser uma boa fórmula para aprimorar o ainda precário controle de qualidade do ensino superior" (FOLHA DE S. PAULO, 2006).

\section{Considerações Finais}

A pesquisa realizada na imprensa escrita no período 1995 a 2010, mostra que a educação não é uma temática muito destacada nas revistas, mas é frequente 
no jornal. Acerca da educação, os assuntos considerados são, principalmente, relativos à qualidade do ensino, com destaque para a baixa qualidade do ensino básico público e do ensino superior privado. Outras temáticas desenvolvidas são a reserva de vagas em instituições públicas de ensino superior, a (má) formação dos professores, a informática e materiais didáticos padronizados como possíveis ferramentas de melhoria do ensino, a necessidade de políticas meritocráticas de recompensa aos professores. Dentro da temática da qualidade do ensino é que aparece a avaliação.

As mídias analisadas destacam a importância das provas como um elemento de aferição da qualidade da educação, visando sua melhoria. Essa é a sua mensagem principal, ela é reforçada e legitimada. Parece que isso basta, pois os resultados das avaliações não parecem ser tão importantes como o fato em si de se fazer avaliações. Mas há diferenças quanto ao tratamento dado pelas mídias aos resultados obtidos nas provas. A Folha de S. Paulo enfatiza menos a avaliação dentre as outras notícias educacionais, mas, quanto o faz, divulga e analisa os resultados obtidos pelas instituições/cursos. Nas revistas, os resultados das avaliações aparecem apenas como ilustração, principalmente de ideias acerca da baixa qualidade da educação no país.

A concepção de avaliação que se infere nas matérias analisadas e a de avaliação como controle do trabalho desenvolvido pelas instituições e os professores, contribuindo assim a divulgar a visão gerencialista da educação, hegemônica na década de 1990, com o desenvolvimento do Estado Avaliador. Não são consideradas outras formas de avaliação como a institucional. As provas são indicadores de qualidade, sem questionar o que é avaliado, nem o contexto da instituição ou curso. Refletem a concepção de avaliação segundo a qual, os resultados das avaliações dos alunos são aplicáveis à avaliação dos cursos e instituições. As provas, nas matérias analisadas, são consideradas positivas por permitir a elaboração de ranques e estimular a concorrência institucional, o que é considerado bom para a melhoria da qualidade do ensino.

Nas revistas Veja e Época, enfatiza-se a ideia de que a prova é boa, seja ela o Exame Nacional de Cursos-Provão, o Sistema Nacional de Avaliação da Educação Básica- SAEB ou o Exame Nacional de Ensino Médio - ENEM, esse, inclusive como vestibular. Chama a atenção, perante esse destaque à positividade da prova, que não exista nenhuma matéria no universo pesquisado, que faça referência aos conteúdose às temáticas avaliadas. Quanto à validade das provas para aferir qualidade e os questionamentos às provas em larga escala, (como são o SAEB, o ENEM, o PROVÃO e o ENADE) algumas delas aparecem, mas apenas na revista Veja, cujo colunista principal acerca de educação, Claudio 
de Moura Castro, assinala o risco de induzir currículum e de gerar cursinhos de preparação para a prova.

Um destaque merece o Exame Nacional de Cursos. Verifica-se, no estudo, o sucesso do apelido "Provão", criado pelos estudantes que o boicotavam e que foi adotado pelo MEC para o ENC, em vez de combatido. Com efeito, para a mídia, ele é sinônimo de "avaliação", qualquer avaliação: não apenas do ensino superior, não apenas avaliação dos sistemas educacionais. Todo um sucesso de marketing.

Quanto aos períodos analisados, correspondentes aos governos FHC e Lula, percebem-se diferenças quanto a algumas temáticas educacionais priorizadas, devidas às ênfases especificas dos respectivos governos.

A avaliação, se considerada como "prova" é uma temática presente nos governos dos dois ex-presidentes. Nos governos FHC, a avaliação é um assunto muito presente, em consonância com a emergência do Estado Avaliador, e com a introdução de uma nova sistemática: o Provão. O ENADE não terá tanto sucesso quanto o Provão, em parte devido ao fato de ele ser um eixo dentro de um sistema de avaliação (o SINAES), mas também porque, a partir de 2003, atemática da ampliação do acesso ao ensino superior com a inclusão de cotas no ensino superior público ganha maior destaque nas notícias. A avaliação como prova, revigora com a transformação do ENEM em vestibular, em 2010 e é temática muito destacada relativa à educação básica, com a implantação do IDEB.

Pode se concluir, a partir dos dados da pesquisa que as revistas Veja e Época e o jornal Folha de S. Paulo tem contribuído para a legitimação de a avaliação realizada na forma privilegiada de provas aplicadas aos alunos. Assim, nas matérias analisadas, ressalta-se a ideia de que avaliação é uma prova que permite controlar a qualidade da educação.

\section{Referências}

AMARAL, Luis Henrique. As lições nota 100. Veja, São Paulo, n. 1731, p.116-7, 19 dez, 2001.

AMORIM, Ricardo. Reforma incompleta. Época, Rio de Janeiro, n. 354, p. 23, fev. 2005.

ARANHA, Ana. As metas vão pegar. Época, Rio de Janeiro, n. 460, p. 12, mar. 2007a. 
ARANHA, Ana. Como avaliar sua escola. Época, Rio de Janeiro, n. 572, p. 5, maio, 2009.

ARANHA, Ana. Quanto custa educar direito? Época, Rio de Janeiro, n. 466, p. 23 , abr. 2007 b.

ARANHA, Ana; CLEMENTE, Isabel. Ele vai salvar a Educação? Época, Rio de Janeiro, n. 467, p. 30, abr. 2007.

BANÉ, Marco. Ele tropicalizou os notebooks. Época, Rio de Janeiro, n. 470, p. 21, maio, 2007.

BETTI, Renata. Do Ceará para o ITA. Veja, São Paulo, n. 2.087, p. 100-1, 19, nov, 2008.

BOCK, Ana Mêrces Bahia Bock. O provão não é avaliação. Folha de S.

Paulo, São Paulo, 2 dez. 1996. Disponível em: <http://www1.folha.uol.com. br/fsp/1996/12/02/cotidiano/16.html>. Acesso em: 12 jan. 2012.

BRASIL, Lei 10.861, 14/4/2004. Institui o Sistema Nacional de Avaliação da Educação Superior (SINAES) e dá outras providências.

CAMAROTTI, Gerson. Vestibular para sair da faculdade. Veja, São Paulo, n. 1.469 , p.120-3, nov. 1996.

CASTRO Maria Helena Guimarães de. Entrevista: premiar o mérito. Veja, São Paulo, n. 2.047, p. 9-13, fev. 2008.

CASTRO, Claudio de Moura. Novo termômetro da educação. Veja, São Paulo, n. 2.010, p. 20, maio, 2007.

CASTRO, Claudio de Moura. O brasileiro da Nokia. Veja, São Paulo, n. 1.965 , p. 22, mar. 2006.

CASTRO, Claudio de Moura. O meu ministério por um termômetro. Veja, São Paulo, n. 1.474, p. 150, dez. 1996.

CASTRO, Cláudio de Moura. O que dizem os testes. Veja, São Paulo, n. 1.630, p. 21, jan. 2000.

CASTRO, Cláudio de Moura. Porque defendo o Provão? Veja, São Paulo, n. 1.816, p. 22, ago. 2003. 
CASTRO, Claudio de Moura. Qualidade ou inovação? Veja, São Paulo, n. 1.945, p. 23, mar. 2006.

CASTRO, Cláudio de Moura. Quem tem medo de avaliação? Veja, São Paulo, n. 1.759, p. 20, jul. 2002.

CASTRO. Claudio de Moura. Lições de Provão. Veja, São Paulo, n. 1.559, p. 23, ago. 1998.

CIVITA, Roberto. Melhoria na educação. Veja, São Paulo, n. 1.425, p. 102, jan. 1996.

CRUZ, Angélica Santa. Mapa do caos. Veja, São Paulo, n. 1.576, p. 94-5, dez. 1998.

COTES, Paloma. Fábrica de analfabetos. Época, Rio de Janeiro, n. 267, jun. 2003a. Disponível em: $<$ http://revistaepoca.globo.com/Revista/ Epoca/0,EMI38483-15228,00-FABRICA+DE+ANALFABETOS.html>. Acesso em: 15 jun. 2010.

COTES, Paloma. Um pé lá, um cá. Época. Rio de Janeiro, n. 276, 28, ago, 2003b. Disponível em: <http://revistaepoca.globo.com/Revista/ Epoca/0,EMI39631-15228,00-UM+PE+LA+UM+CA.html>. Acesso em 19 jun. 2010.

COTES, Paloma; CARVAS, Camila. Internet: o que muda na escola? Época, Rio de Janeiro, n. 338, nov. 2004. Disponível em: <http:// revistaepoca.globo.com/Revista/Epoca/0,EMI47270-15228,00INTERNET+O+QUE+MUDA+NA+ESCOLA.html>. Acesso em: 10 ago. 2010.

COTES, Paloma; MONTEIRO, Beatriz. A chance de vencer o atraso no ensino. Época, Rio de Janeiro, n. 461, mar. 2007. Disponível em: <http:// revistaepoca.globo.com/Revista/Epoca/0,EMI56537-15228,00-A+CHAN $\mathrm{CE}+\mathrm{DE}+\mathrm{VENCER}+\mathrm{O}+\mathrm{ATRASO}+\mathrm{NO}+\mathrm{ENSINO}$.html $>$. Acesso em: 18 set. 2010.

DUARTE, Sara. A internet na sala de aula. Época, Rio de Janeiro, n. 315, maio, 2004. Disponível em: < http://revistaepoca.globo.com/Revista/ Epoca/0,EMI44575-15228,00-INTERNET+NA+SALA+DE+AULA. html.>_Acesso em: 12 maio, 2012. 
ÉPOCA. Rio de Janeiro, n. 277, set. 2003.

FERNANDES, Nelitto. Será que as cotas resolvem? Pergunte a Jéssica. Época, Rio de Janeiro, n. 409, mar. 2006. Disponível em: <http:// revistaepoca.globo.com/Revista/Epoca/0,EMI53489-15228,00-SERA+QUE + AS+COTAS+RESOLVEM+PERGUNTE+A+JESSICA.html $\geq$. Acesso em: 11 nov. 2010.

FERREIRA, Sérgio Henrique. Por uma avaliação permanente. Folha de S. Paulo, São Paulo, 8 nov. 1996. Disponível em http: <//www1.folha.uol.com. br/fsp/1996/11/08/opiniao/9.html>. Acesso em: 12 jan. 2012.

FINKENZELLER, Karin. Bem vindos ao A. Veja, São Paulo, n. 1.642, p.164-5, mar. 2000 .

FOLHA DE S. PAULO. Editorial. Cursos Monitorados. Folha de S. Paulo, São Paulo, 17 maio, 2006. Disponível em: < http://www1.folha.uol.com.br/ fsp/opiniao/fz1705200603.htm>. Acesso em: 12 abr. 2011.

FOLHA DE S. PAULO. Editorial. O Provão 2. Folha de S. Paulo, São Paulo, 1 jul. 1997a. Disponível em: <http://www1.folha.uol.com.br/fsp/ opiniao/fz010703.htm>. Acesso em: 15 jan. 2012.

FOLHA DE S. PAULO. Editorial. Provão e o futuro do ensino. Folha de $\mathbf{S}$. Paulo, São Paulo, 21 dez. 1997b. Disponível em: <http://www1.folha.uol. com.br/fsp/opiniao/fz211201.htm> Acesso em: 15 jan. 2012.

FOLHA DE S. PAULO. $2^{\circ}$ grau terá provão para avaliar escolas. Folha de S. Paulo, São Paulo, 3 jul. 1997c. Disponível em http: <//www1.folha.uol.com. br/fsp/cotidian/ff030742.htm>. Acesso em: set. 2011.

FOLHA DE S. PAULO. Alunos de $4^{\mathrm{a}}$ e $8^{\mathrm{a}}$ séries fazem provão. Folha de $\mathbf{S}$. Paulo, São Paulo, 18 abr. 1997d. Disponível em: <www1. folha.uol.com.br/ fsp/cotidian/ff180423.htm>. Acesso em: 18 ago. 2011.

FOLHA DE S. PAULO. Avaliação do MEC mostra $2^{\circ}$ grau "sofrível". Folha de S. Paulo, São Paulo, 27 mar. 1998a. Disponível em: <www1.folha.uol. com.br/fsp/cotidian/ff27039831.htm>. Acesso em: 17 set. 2011.

FOLHA DE S. PAULO. Editorial. Despreparo criminoso. Folha de S. Paulo, São Paulo, 10 jun. 1998b. Disponível em: <www1.folha.uol.com.br/ fsp/opiniao/fz10069801.htm>. Acesso em: 17 set. 2011. 
FOLHA DE S. PAULO. Em "provão", paciente do SUS "reprova" HC de SP. Folha de S. Paulo, São Paulo, 7 mar. 2009. Disponível em: <http://www1. folha.uol.com.br/fsp/saude/sd0703200901.htm>. Acesso em: 10 jul. 2011.

FRANCO, Marina. Três diplomas no tempo de um. Época, Rio de Janeiro, n. 619, mar. 2010. Disponível em: <http:// revistaepoca.globo.com/Revista/Epoca/0,EMI129300-15223,00TRES+DIPLOMAS+NO+TEMPO+DE+UM.html>. Acesso em: 12 fev. 2011.

FRUTUOSO, Suzane. De volta à terra. Época, Rio de Janeiro, n. 339, nov. 2004. Disponível em: <http://revistaepoca.globo.com/Revista/ Epoca/0,EMI47378-15228,00-DE+VOLTA+A+TERRA.html>. Acesso em: 18 set. 2010.

GÓIS, Anselmo. Provão começa neste ano. Veja, São Paulo, n. 1.449, p. 567, jun. 1996.

GUIMARÃES, Camila. A falha não é do Enem. Época, Rio de Janeiro, n. 638, ago. 2010. Disponível em: <http://revistaepoca.globo.com/Revista/ Epoca/0,EMI161300-15223,00-A+FALHA+NAO+E+DO+ENEM.html>. Acesso em: 20 abr. 2011.

LEITE, Paulo Moreira. Cotas do num país mestiço. Época, Rio de Janeiro, n. 249, fev. 2003. Disponível em: <http://revistaepoca.globo.com/Revista/ Epoca/0,EMI35807-15217,00-CARTA+DO+EDITOR.html>. Acesso em: 12 ago. 2010.

ONIGRE, Eduardo. O rosto do ensino. Veja, São Paulo, n. 1.493, p. 86-7, abr. 1997.

RANGEL, Rogério. Demóstenes Torres: "O projeto das cotas é um estatuto racista". Época, Rio de Janeiro, n. 559, fev. 2009. Disponível em: <http:// revistaepoca.globo.com/Revista/Epoca/0,EMI25351-15223,00-DEMOSTE NES+TORRES+O+PROJETO+DAS+COTAS+E+UM+ESTATUTO+RACI STA.html>. Acesso em: 10 jan. 2011.

ROTHEN, José Carlos. O vestibular do Provão. Avaliação, Campinas, v. 8, n. 1, p. 27-37, 2003. 
SILVA JÚNIOR, Orlando Silva. Zero para o provão. Folha de S. Paulo, São Paulo, 5 nov. 1996. Disponível em: <www1.folha.uol.com.br/ fsp/1996/11/05/opiniao/8.html>. Acesso em: 18 ago. 2011.

TAVARES, Graça et al. Políticas de expansão da educação superior no Brasil Pós LDB/96. Desafios para a avaliação. Inter-ação, Goiânia, v. 36, p. 81100, 2011.

TERMERO, Maria. Professor empresa. Época, Rio de Janeiro, n. 306, mar. 2004. Disponível em: <http://revistaepoca.globo.com/Revista/ Epoca/0,EMI103900-15223,00-PROFESSOREMPRESA.html>. Acesso em: 18 set. 2010 .

VASCONCELOS, Lia. O efeito do Enem nos vestibulares.

Época, Rio de Janeiro, n. 502, dez. 2007. Disponível em: <http:// revistaepoca.globo.com/Revista/Epoca/0,„EMI59576-15223,00$\mathrm{O}+\mathrm{EFEITO}+\mathrm{DO}+\mathrm{ENEM}+\mathrm{NO}+\mathrm{VESTIBULAR} \cdot \mathrm{html}>$. Acesso em: $27 \mathrm{jan}$. 2011.

VEJA. A última prova. Veja, São Paulo, n. 1.384, p. 48, mar. 1995a.

VEJA. Exame Nacional de Cursos. Veja, São Paulo, n. 1.455, p. 57, jul. 1996.

VEJA. O caminho das Minas. Veja, São Paulo, n. 1.379, p. 25, fev. 1995b.

VEJA. Um bom exemplo. Veja, São Paulo, n. 1.580, p. 64, jan. 1999.

VICÁRIA, Luciana. A opção de estudar fora. Época, Rio de Janeiro, n. 495, nov. 2007. Disponível em: $<$ https://spreadsheets0.google.com/ccc?key=t5Dx 66PmS5C97S1TT7xXxvw\&hl=pt_BR\#gid=5>. Acesso em: 20 jan. 2011.

VICÁRIA, Luciana. Qual é a nota do seu colégio? Época, Rio de Janeiro, n. 517, abr. 2008. Disponível em: <http://revistaepoca.globo.com/Revista/ Epoca/0,EMI5105-15223,00-QUAL+E+A+NOTA+DE+SEU+COLEGIO. html>. Acesso em: 20 jan. 2011.

VICÁRIA, Luciana; CORDEIRO, Tiago. Uma geração desperdiçada.

Época, Rio de Janeiro, n. 252, mar. 2003. Disponível em: <http:// revistaepoca.globo.com/Revista/Epoca/0,EMI36176-15228,00UMA+GERACAO+DESPERDICADA.html>. Acesso em: 12 fev. 2010. 
WEINBERG, Mônica. As notas do Provão dos 260 melhores cursos superiores. Veja, São Paulo, n. 1.847, p. 84-95, mar. 2004.

WEINBERG, Mônica. Recorde Histórico. Veja, São Paulo, n. 1.680, p. 98, dez. 2000.

José Carlos Rothen - Universidade Federal de São Carlos São Carlos | SP | Brasil. Contato: josecarlos@rothen.pro.br

Gladys Beatriz Barreyro - Universidade de São Paulo São Paulo | SP | Brasil. Contato: gladysb@usp.br

Aryane de Paula Prado - Universidade de São Paulo São Paulo | SP | Brasil. Contato: aryaneufscar@yahoo.com.br

Leticia Bortolin- Universidade de São Paulo São Paulo | SP | Brasil. Contato: leticia_bortolin@hotmail.com

Raiani Cristina Cavachia - Universidade de São Paulo São Paulo | SP | Brasil. Contato: raianicavichia@hotmail.com

Artigo recebido em 3 de junho de 2014 e aprovado em 8 de julho de 2014 . 